\title{
JOURNAL.RU
}

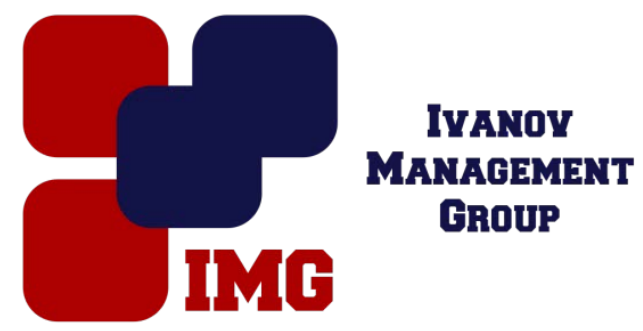

Герасименко Е.Ю., Переходов М.В., Кобец В.А. Донской Государственный Технический Университет Ростов-на-Дону, Россия

doi: 10.18411/lj-28-02-2017-1-03

idsp 000001:lj-28-02-2017-1-03

\section{Исследование динамики трибоэлектрохимического процесса на плоскости}

\section{Аннотация}

В данной работе исследуется динамика трибоэлектрохимического процесса на плоскости.

Ключевые слова: трибоэлектрохимический процесс, аттракционная сила, сила трения скольжения.

В работе рассматриваются вопросы динамики одномерного трибоэлектрохимического процесса на плоскости. Схема исследования трибоэлектрохимического процесса представлена на рисунке 1.

Уравнение движения в векторной форме имеет вид

$$
m \frac{d V}{d t}=m \bar{g}+\bar{N}+\overline{F_{a}}+\overline{F_{\mathrm{T}}},
$$

где $\bar{N}$ - реакция плоскости; $\overline{F_{\mathrm{T}}}$ - сила трения скольжения; $\overline{F_{a}}$ - аттракционная сила, возникающая на электролитной смазке

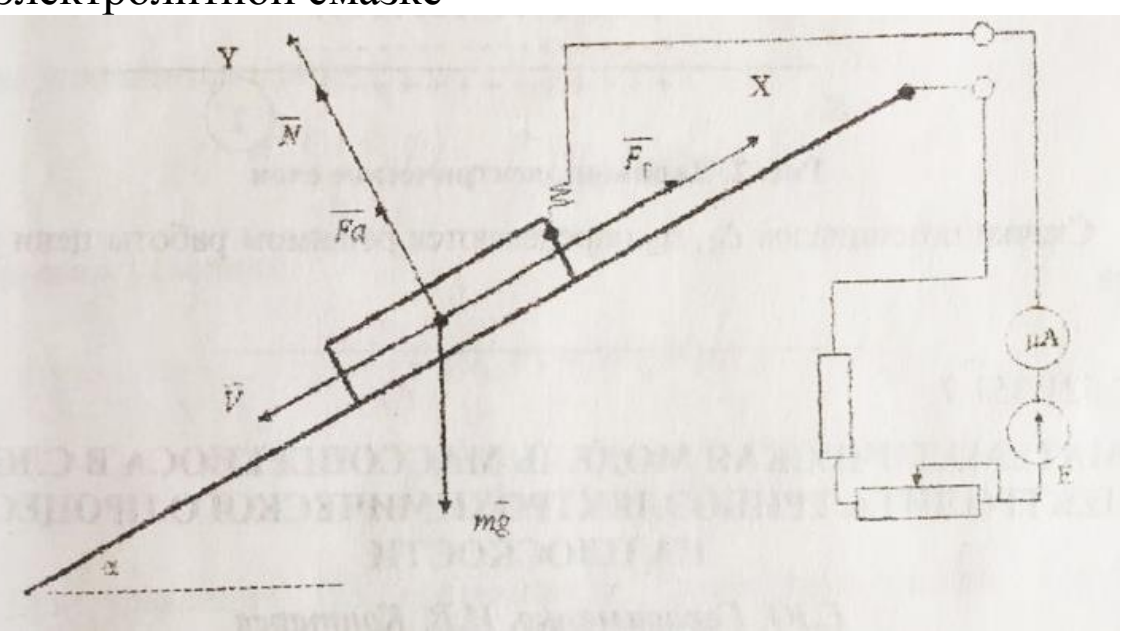

Рис.1. Одномерный трибоэлектрохимический прочесс.

Проецирование векторного уравнения (1) на оси координат дает систему уравнений 


$$
\left\{\begin{array}{c}
m \frac{d V}{d t}=-m g \sin \alpha+\mu N, \\
0=N+F_{a}-m g \cos \alpha,
\end{array}\right.
$$

где $\mathrm{V} \equiv|\bar{V}|, g \equiv|\bar{g}|, \quad N \equiv|\bar{N}|, F_{a} \equiv\left|\overline{F_{a}}\right| ; \mu$-коэффициент трения скольжения. Система дает

$$
\begin{gathered}
\mathrm{N}=m g \cos \alpha-F_{a},(2) \\
\frac{d V}{d t}=\frac{\mu}{m} F_{a}+g(\sin \alpha-\mu \cos \alpha) .
\end{gathered}
$$

Аттракционная сила $\overline{F_{a}}$ имеет электростатическую природу и может быть приближено рассчитана.

Она приближенно может быть рассчитана как результат взаимодействия макро точки (тела) с бесконечной в обе стороны плоскостью:

$$
F_{a}=\frac{C_{g e 1} C_{g e} \theta S_{1} \Delta_{1} \Delta_{2}}{\pi \varepsilon l},
$$

Где $C_{g c i}, C_{g c 2}$ - удельные электрические емкости двойных электрических слоев, указанных на рис. $2 ; \theta$-ширина наклонной плоскости; $S_{1}$-площадь опоры движущегося тела; $\Delta_{1}, \Delta_{2}$ - скачки электрических потенциалов на 1-м и 2-м двойных электрических слоях; $\varepsilon$ - диэлектрическая проницаемость электролитной смазки; l- толщина слоя смазки.

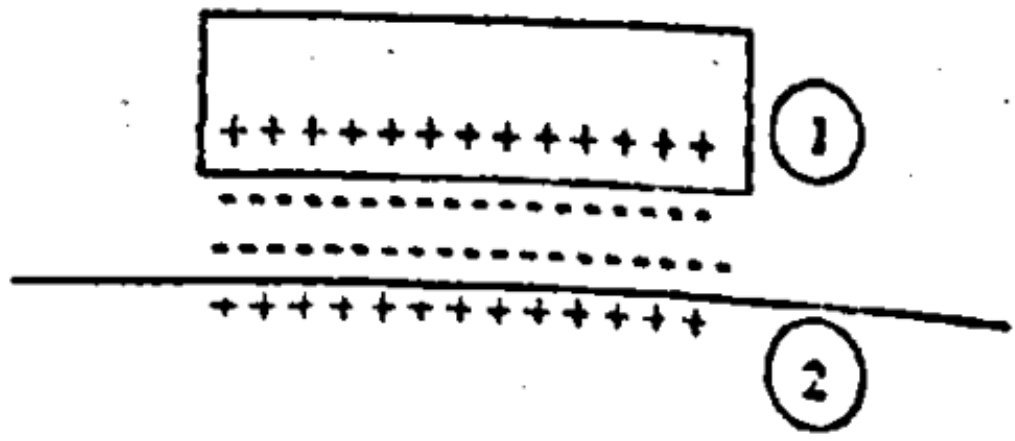

Рис.2. Двойные электрические слои

Скачки потенциалов $\Delta_{1} \Delta_{2}$ будут определяться режимом работы цепи управления.

\section{Литература}

1. Л.И.Антропов «Теоретическая механика» 